\title{
Effect of age and blood pressure on aortic size and stroke distance
}

\author{
BASIM A TOWFIQ, J JAMIE WEIR, $\dagger$ JOHN M RAWLES $\ddagger$ \\ From ${ }^{\star}$ Raigmore Hospital, Inverness, $†$ Department of Radiology, Aberdeen Royal Infirmary, and $\ddagger$ Department \\ of Medicine, University of Aberdeen
}

SUMMARY The diameters of the ascending and descending aorta at the level of the carina were measured from computerised tomograms in 200 adults without cardiac or aortic disease. At all ages the ascending aorta had a greater cross sectional area than the descending aorta, and both areas increased significantly with age. The increase was proportionately greater in the descending than in the ascending aorta and the percentage changes were similar in males and females, the latter having a smaller mean descending aortic diameter. The extent of the increase in cross sectional area of the aorta is sufficient to explain the observed fall of stroke distance that occurs with age. The effect of changing blood pressure on aortic cross sectional area, and hence the relation between stroke distance and stroke volume, was calculated from published data on aortic compliance at different ages. Assuming constant peripheral resistance, stroke distance would change by 34,82 , and $94 \%$ for a $100 \%$ change of stroke volume at age 20,50 , and 80 respectively. At age $\mathbf{8 0}$ the aorta behaves like a rigid pipe but at age 20 its elasticity is such that constancy of aortic size cannot be assumed.

Volumetric cardiac output may be measured noninvasively by means of echocardiography to measure aortic diameter and Doppler ultrasound to measure aortic blood velocity. ${ }^{1-4}$ Left ventricular stroke volume is calculated as the product of aortic cross sectional area and the systolic velocity integral or aortic blood flow. The measurement of velocity is simple and highly reproducible, ${ }^{5-7}$ but measurement of aortic cross sectional area is technically difficult and is the least reproducible part of the procedure. ${ }^{8-10}$ In intervention studies it would therefore be simpler to make a single measurement of aortic diameter and assume that it is constant. ${ }^{311}$ We have gone further and have suggested that the measurement may be dispensed with entirely and velocity measurements used by themselves to measure linear, as opposed to volumetric, cardiac output. ${ }^{1213}$ The systolic velocity integral is then known as stroke distance and its product with heart rate as minute distance. These are analogous to stroke volume and cardiac output respectively. An aortic cross sectional area that is reasonably constant is a prerequisite for the

Requests for reprints to Dr John M Rawles, Department of Medicine, University of Aberdeen, Foresterhill, Aberdeen AB9 2ZB.

Accepted for publication 17 February 1986 use of stroke distance either as an absolute measure of cardiac output or for measuring serial changes.

In normal adults peak aortic blood velocity, stroke distance, and minute distance decline with age. ${ }^{13} 14$ This could result from a reduction of volumetric cardiac output or an increase in aortic cross sectional area, and the relative importance of these two factors is not clear. We have therefore measured the diameters of the ascending and descending aorta in 200 adult patients in order to determine the effect of age on aortic cross sectional area and to see whether any increase in size with age is sufficient to account for the observed fall of aortic blood velocity.

In the short term, blood pressure is an obvious factor that might affect aortic size and hence aortic blood velocity. In 1937, long before Doppler ultrasound was used, Hallock and Benson studied the pressure-volume relation of segments of thoracic aortas from subjects of different ages, ${ }^{15}$ and raw data from their work are published in reference 16. From these data we have calculated the effect of changes of blood pressure on aortic blood velocity and stroke distance at different ages. In 1967, Bader published a similar though more comprehensive study using complete thoracic aortas, with a detailed statistical analysis. ${ }^{17}$ The information in his paper makes 


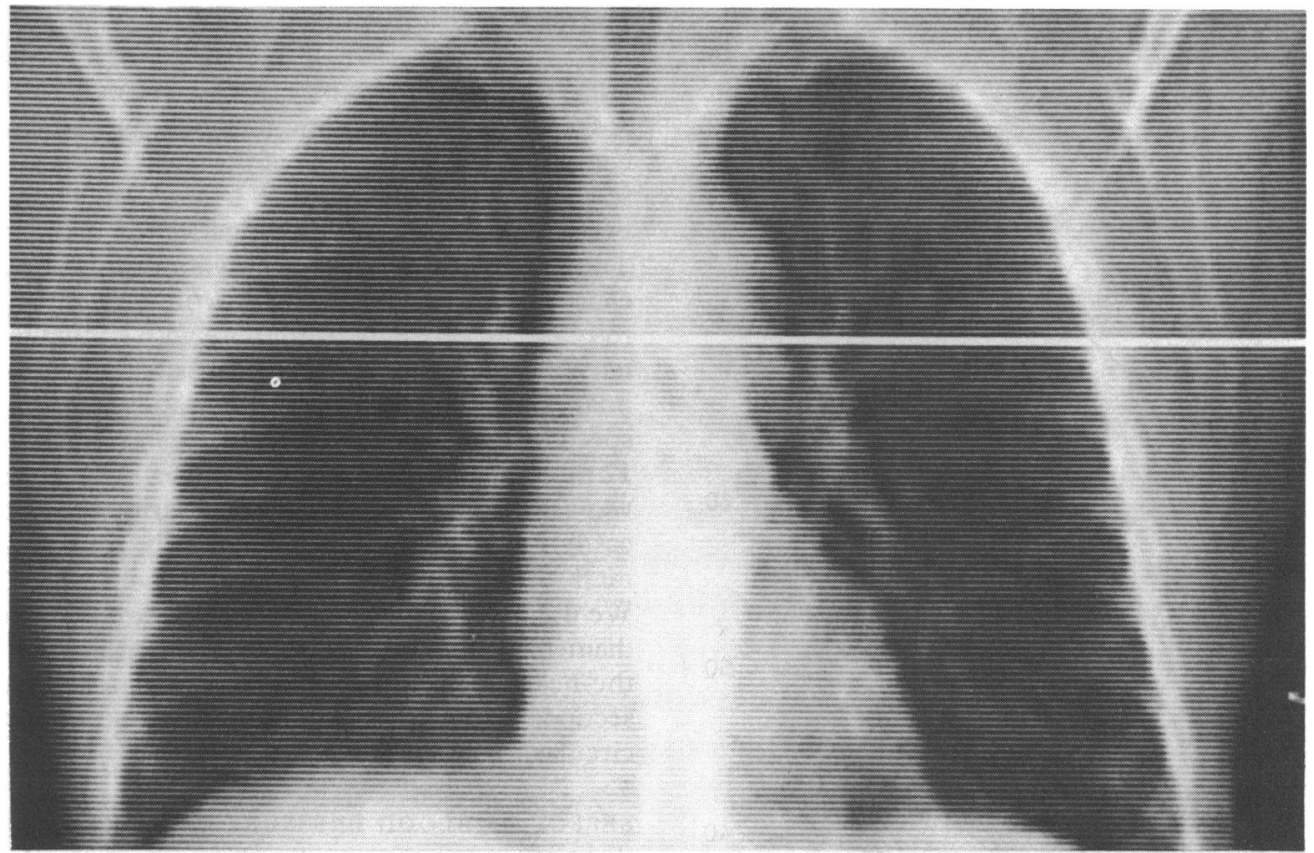

Fig. 1 A computerised tomogram of the chest showing the horizontal level of the carina.

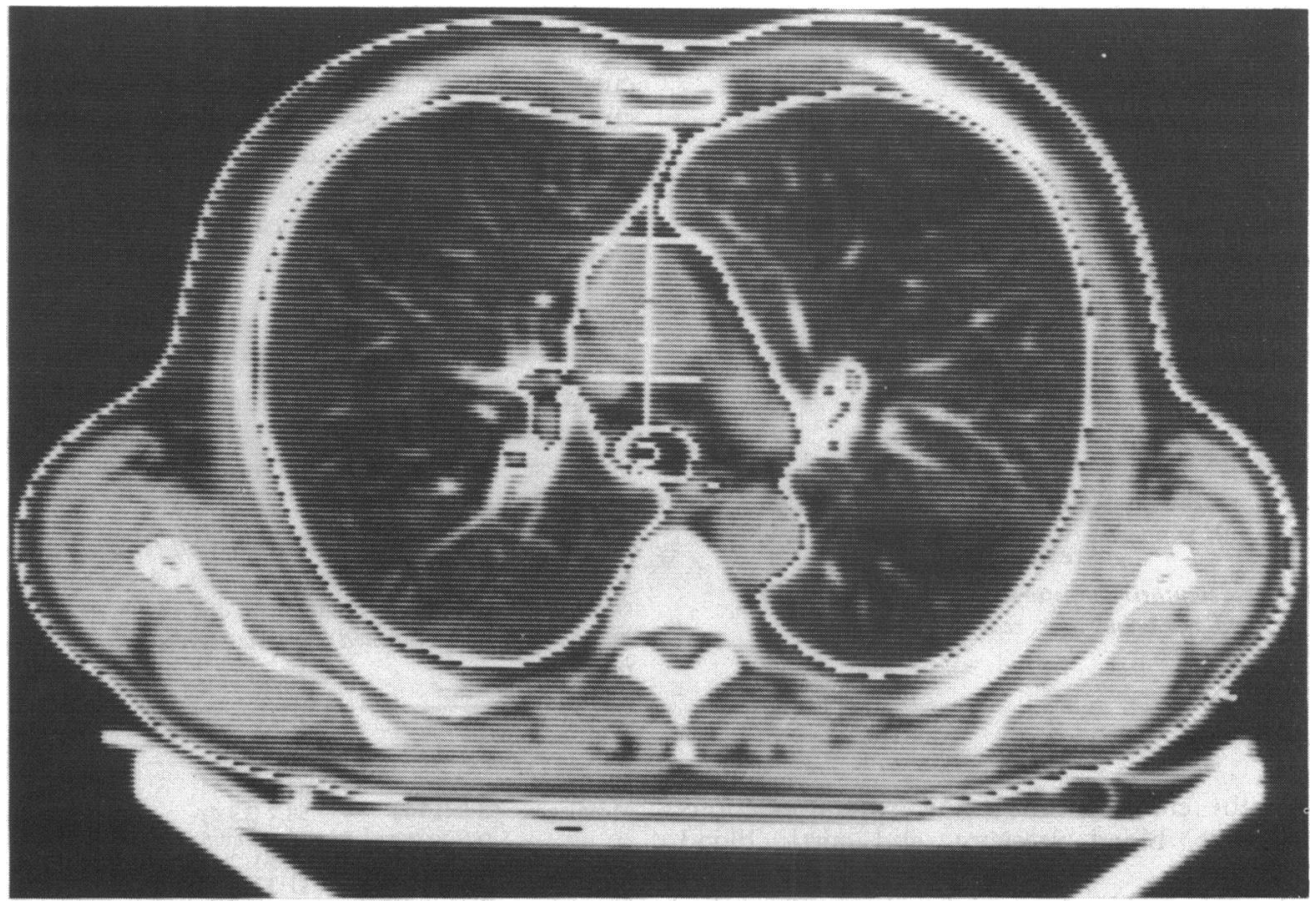

Fig. 2 Computerised tomogram of the chest at the level of the carina looking cephalad. The bifurcation of the trachea is seen posterior to cursor 2. The external diameter of the ascending aorta is obtained from the distance between the cursors which mark its anterior and posterior boundaries. The descending aorta is seen to the left of the patient's spine. 


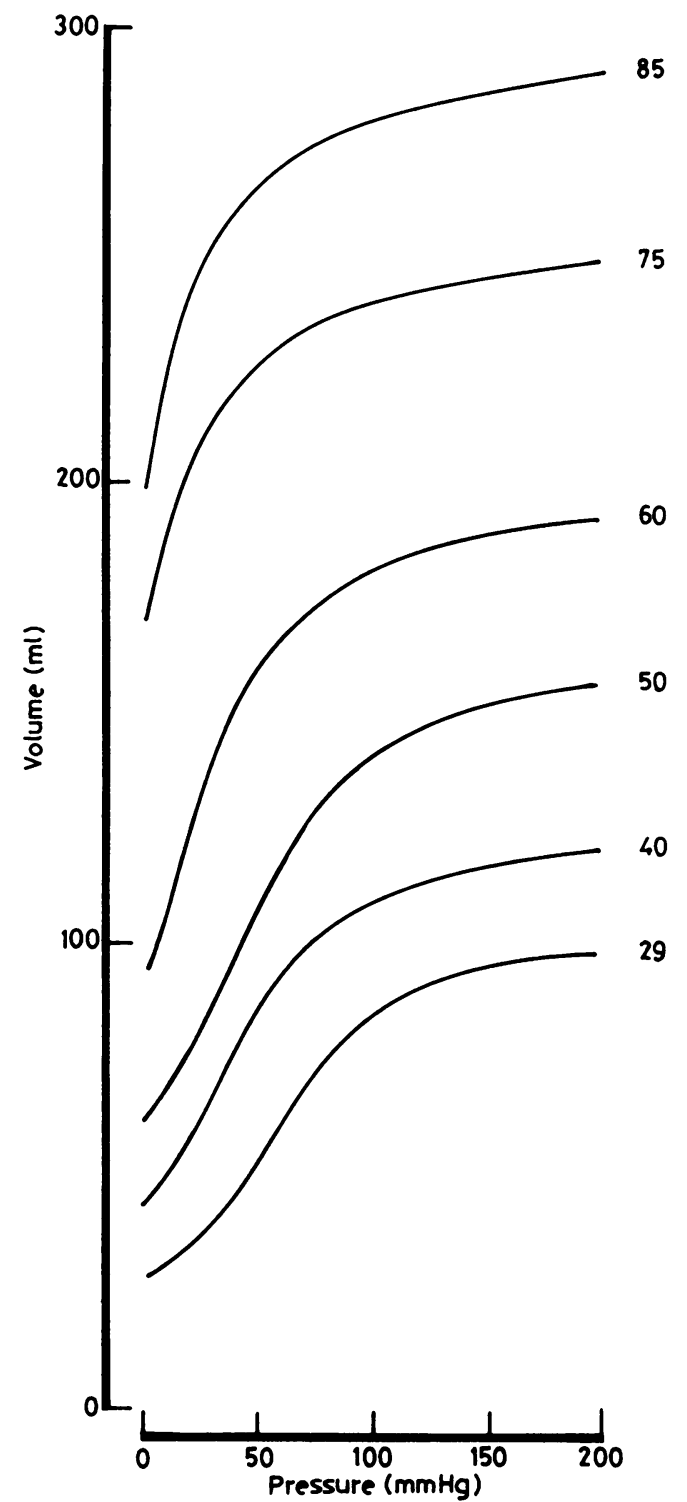

Fig. 3 Representative pressure-volume curves for the thoracic aorta at various ages, redrawn from Bader. ${ }^{1}$

possible the computation of the general relations between age, blood pressure, and aortic blood velocity.

In this paper, blood pressure measured in vivo refers to the mean pressure during ejection, and has a value intermediate between systolic and mean blood pressure.

\section{Patients and methods}

\section{MEASUREMENT OF AORTIC DIAMETERS}

A retrospective examination was undertaken of computerised tomograms of the chest from 200 consecutive patients aged 20-82, most of whom had been referred for the investigation of malignancy. Tomograms from patients in whom tumour masses caused distortion of the aortic anatomy were rejected, as were data from those with known hypertension or congenital or valvar cardiac disease. The images were taken in full inspiration with a scan speed of approximately $10 \mathrm{~s}$ and a slice thickness of $12 \mathrm{~mm}$. The horizontal cut at the level of the carina was selected (Fig. 1), because the carina provided an easily recognisable and anatomically reliable landmark. Figure 2 shows a typical image at this level. We used electronic callipers to measure the external diameters of the ascending and descending aorta to the nearest millimetre and we calculated the cross sectional areas by assuming the cross sections to be circular.

\section{EFFECT OF BLOOD PRESSURE ON AORTIC VOLUME}

Bader constructed pressure-volume curves from 27 whole human thoracic aortas from subjects aged 22-85 years. ${ }^{17}$ Figure 3 shows six representative curves that have been redrawn. Hallock and Benson studied the pressure-volume relation in 18 thoracic aorta segments from subjects aged $20-78,15$ and mean volumes at 10 pressures in five age groups are given. ${ }^{16}$ The general appearance of the curves is similar to that in Fig. 3.

\section{Results}

\section{AORTIC CROSS SECTIONAL AREA}

Mean (SD) cross sectional areas of the ascending and descending aorta are given in the Table. In most

Table Mean (SD) cross sectional area $\left(\mathrm{cm}^{2}\right)$ of ascending and descending aorta in men and women. Areas have been calculated from external diameters, and values at ages 20 and 80 have been obtained from the regression equations given in the text

\begin{tabular}{llll}
\hline & Men & Women & \multicolumn{1}{l}{ All } \\
\hline No & 133 & 67 & 200 \\
Mean age & $58.8(13.7)$ & $58.7(13.4)$ & $58.8(13.6)$ \\
& Cross sectional area of ascending aorta & \\
Age 20 & $5.71(1.59)$ & $5.30(2.41)$ & $5.57(1.84)$ \\
Age 80 & $11.44(1.55)$ & $11.32(2.32)$ & $11.40(1.82)$ \\
Mean & $9.41(2.01)$ & $9.18(2.61)$ & $9.33(2.23)$ \\
& Cross sectional area of descending aorta & \\
Age 20 & $3.21(1.23)$ & $2.16(1.40)$ & $2.86(1.31)$ \\
Age 80 & $7.40(1.20)$ & $6.73(1.34)$ & $7.17(1.29)$ \\
Mean & $5.92(1.52)$ & $5.10(1.64)$ & $5.64(1.61)$ \\
\hline
\end{tabular}




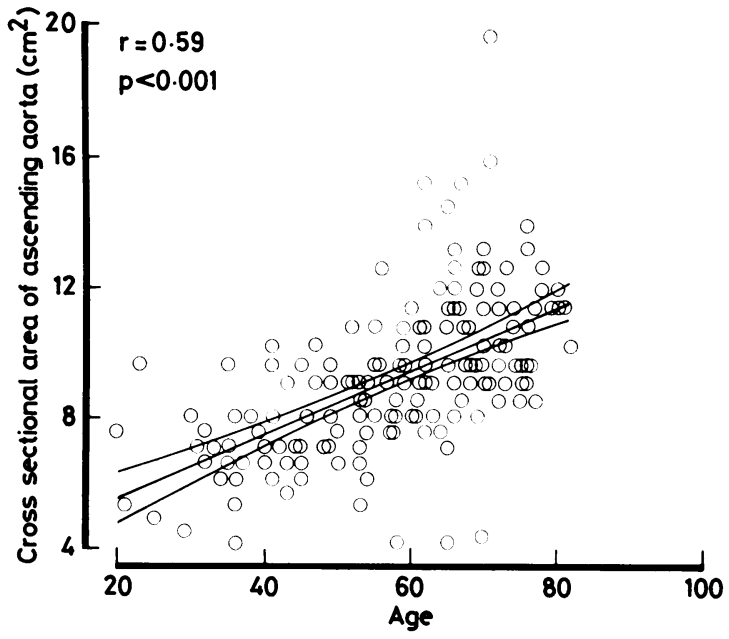

Fig. 4 Cross sectional area of ascending aorta at various ages. The regression line is shown together with its $95 \%$ confidence limits.

cases the ascending aorta was larger than the descending aorta, the mean ratio of the two areas being $1 \cdot 7$. Both sections of the aorta were larger in males than in females. Cross sectional areas of both the ascending and descending aorta increased with age $(r=0.59, p<0.001$ and $r=0.61, p<0.001)$, the regression equations being respectively $y=3.63+0.097 x$, and $y=1.42+0.072 x$ (Figs. 4 and 5 ). Between the ages of 20 and 80 the ascending aorta increased in area by $105 \%$ and the descending aorta increased by $151 \%$.

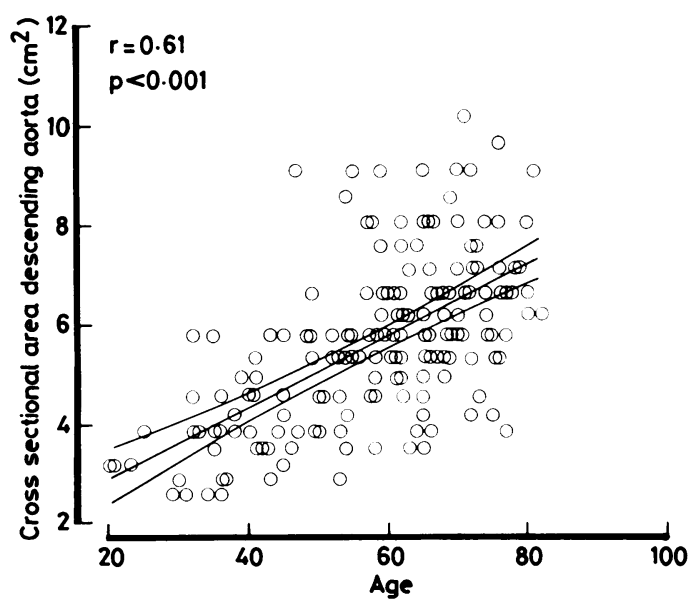

Fig. 5 Cross sectional area of descending aorta at various ages. The regression line is shown together with its $95 \%$ confidence limits.

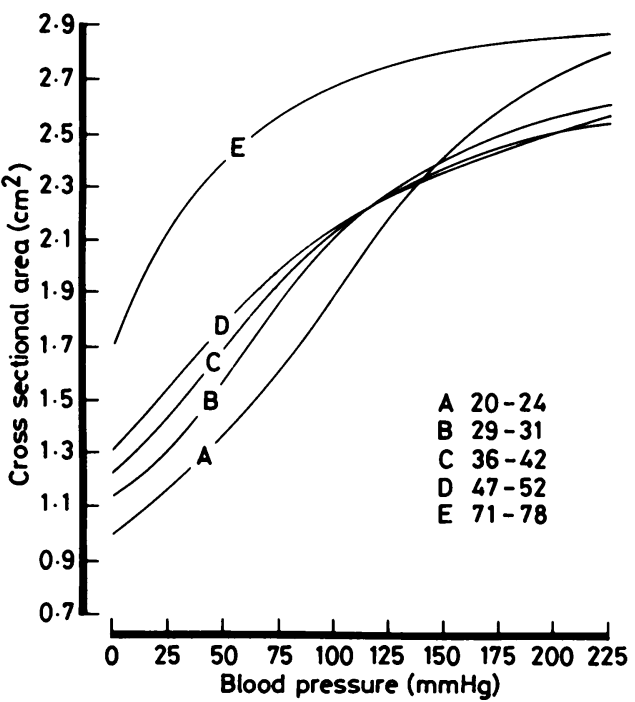

Fig. 6 Calculated effect of mean blood pressure on cross sectional area of thoracic aorta in various age groups, raw data from Hallock and Benson. ${ }^{15} 16$

EFFECT OF BLOOD PRESSURE ON AORTIC CROSS SECTIONAL AREA-DATA FROM HALLOCK AND BENSON ${ }^{1516}$

When an increasing transmural pressure difference causes an elastic tube to expand, it increases in length (1) as well as in cross sectional area (CSA). If the percentage increase in radius equals the per-

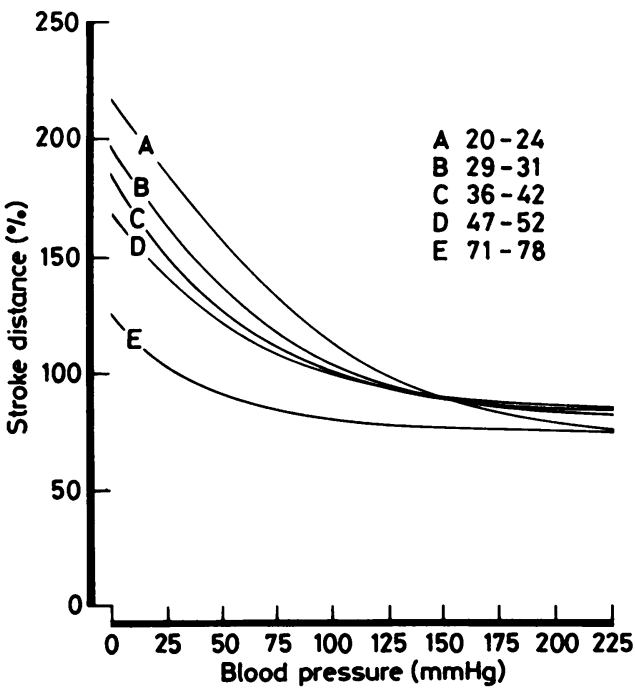

Fig. 7 Calculated effect of mean blood pressure on stroke distance in various age groups, raw data from Hallock and Benson. ${ }^{15} 16$ 


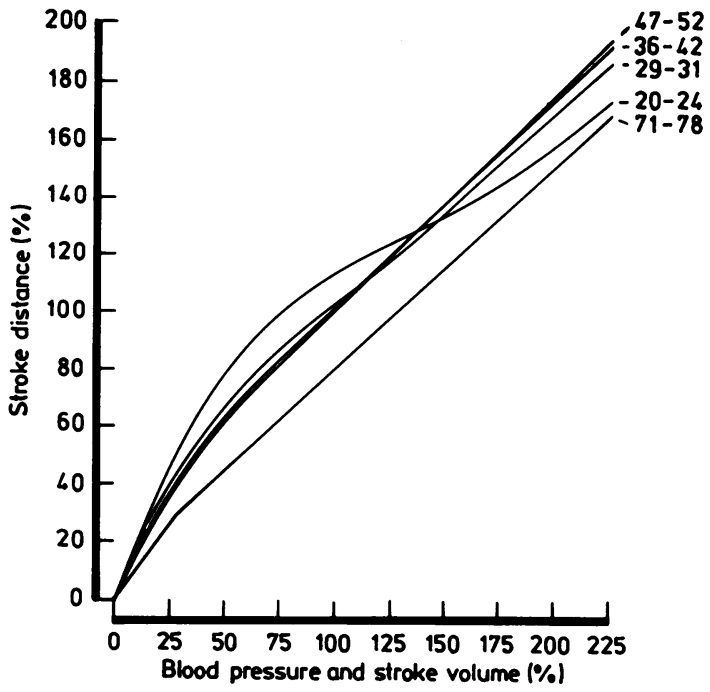

Fig. 8 Calculated effect of concomitant change of mean blood pressure and stroke volume on stroke distance with constant peripheral resistance in various age groups. On the abscissa $100 \%$ represents a mean blood pressure of 100 mm Hg. Raw data from Hallock and Benson. ${ }^{15} 16$

centage increase in length then:

$$
\delta \text { volume } \%^{2 / 3}=\delta \text { CSA } \%
$$

In an elastic tube, however, the longitudinal wall stress is half the tangential wall stress, and in the human aorta the tangential elastic modulus $\left(E_{t}\right)$ is 1.2 times the longitudinal elastic modulus $\left(\mathrm{E}_{1}\right){ }^{17}$ Therefore,

$$
(1+\delta) \text { volume }=\pi(\mathrm{r}(1+\delta))^{2} \times 1(1+0.6(\delta))
$$

We used this equation in an iterative computer method to apportion the increase in volume between cross sectional area and length. Figure 6 shows the calculated effect of blood pressure on cross sectional area. The inflection in the curves is less marked than that in the pressure-volume curves seen in Fig. 3. The cross sectional area at zero pressure increases with age, but at high pressure, except for those from the 71-78 age group, the younger aortas are more distensible and there is a negative relation between age and cross sectional area.

Assuming a flat velocity profile:

Stroke volume $=\mathrm{CSA} \times$ stroke distance

Hence, stroke distance is proportional to the reciprocal of cross sectional area, enabling the effect of blood pressure on stroke distance to be calculated, as shown in Fig. 7. There is a steep rise in stroke distance corresponding to the rapid fall of cross sectional area at low pressures. This occurred at about $125 \mathrm{~mm} \mathrm{Hg}$ in the youngest group (age 20-24), 100 $\mathrm{mm} \mathrm{Hg}$ in the middle aged, and $50 \mathrm{~mm} \mathrm{Hg}$ in the group aged 71-78.

It would be an unusual clinical situation for blood pressure to alter widely without an accompanying change of cardiac output, so Fig. 8 shows the calculated effect on stroke distance of variation of both blood pressure and stroke volume. A constant value of peripheral resistance is assumed, with $100 \%$ on the abscissa representing a mean blood pressure of $100 \mathrm{~mm} \mathrm{Hg}$ and a stroke volume of $100 \%$, and $50 \%$ indicating that both variables are halved in value. There is a virtual straight line relation between stroke volume and stroke distance in the oldest age group, with the aorta behaving like a rigid pipe. In the middle age groups there is displacement of the curves upwards but they then run approximately parallel to the line of the oldest group. In the youngest age group there is a pronounced inflection below $100 \mathrm{~mm} \mathrm{Hg}$, whereas above this pressure the relation is approximately linear, though with a less steep slope than that in the older age groups.

GENERAL RELATION BETWEEN AGE, BLOOD

PRESSURE, CROSS SECTIONAL AREA, AND

STROKE DISTANCE-DATA FROM BADER ${ }^{17}$

The volume of the aorta at zero pressure rises with age (A) as the internal radius $\left(R_{0}\right)$ and length (l) increase. The regression equation for the internal radius at zero pressure is:

$$
R_{0}=5+0.064 \times A
$$

As pressure rises there is a rapid increase of volume until an inflection is reached when the slope of the curve lessens. The pressure $\left(P_{i}\right)$ at the point of inflection is given by

$$
P_{i}=106-32 \times A
$$

which means that $P_{i}=0$ and the inflection disappears at about the age of 80 .

The percentage increase in aortic volume at a pressure of $100 \mathrm{~mm} \mathrm{Hg}$ compared with the volume at zero pressure is given by

$$
\delta \text { volume } \%=234-2 \cdot 27 \times \mathrm{A}
$$

From (2) and (3) the radius at a pressure of $100 \mathrm{~mm}$ $\mathrm{Hg}\left(\mathbf{R}_{100}\right)$ is calculated by iteration as before. Tangential stress in the aortic wall at pressure $\mathbf{P}$ is

$$
\mathrm{S}=0.04 \times \mathrm{P}-0.00035 \times \mathrm{A} \times \mathrm{P}+0.01 \times \mathrm{A}-0.9
$$

and when $P=100 \mathrm{~mm} \mathrm{Hg}$

$$
S_{100}=3 \cdot 1-0.025 \times A
$$

The tangential elastic modulus for pressures around $100 \mathrm{~mm} \mathrm{Hg}$ is given by

$$
E_{t}=A / 2
$$

The radius at pressure $P$ is

$$
\mathbf{R}_{\mathrm{P}}=\mathbf{R}_{100}+\left(\mathrm{S}-\mathrm{S}_{100}\right) \times \mathbf{R}_{100} / \mathrm{E}_{\mathrm{t}}
$$




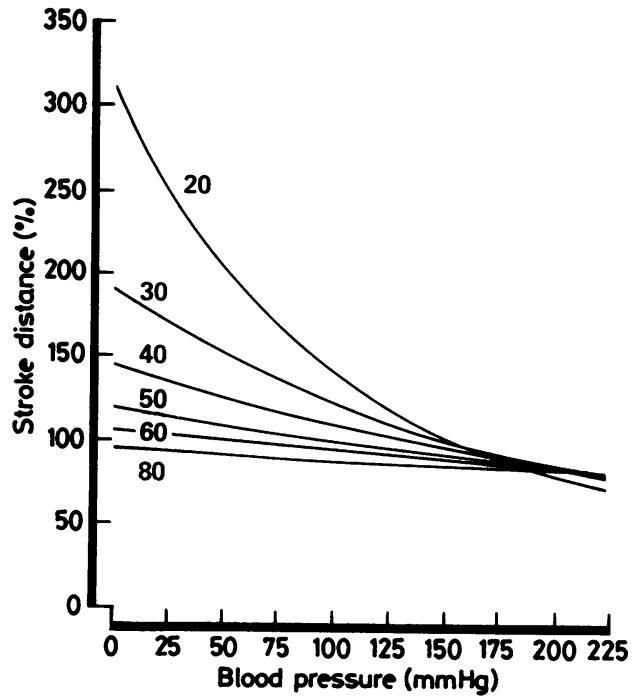

Fig. 9 Computer plot of effect of mean blood pressure on stroke distance at various ages. Raw data from Bader. ${ }^{17}$ Compare with Fig. 7.

Hence, using (1) and (4-7), aortic cross sectional area and stroke distance may be calculated for any age, mean blood pressure, and cardiac output. The prediction becomes less reliable as the pressure departs from $100 \mathrm{~mm} \mathrm{Hg}$ because the simple relation between $E_{t}$ and age only holds exactly at that

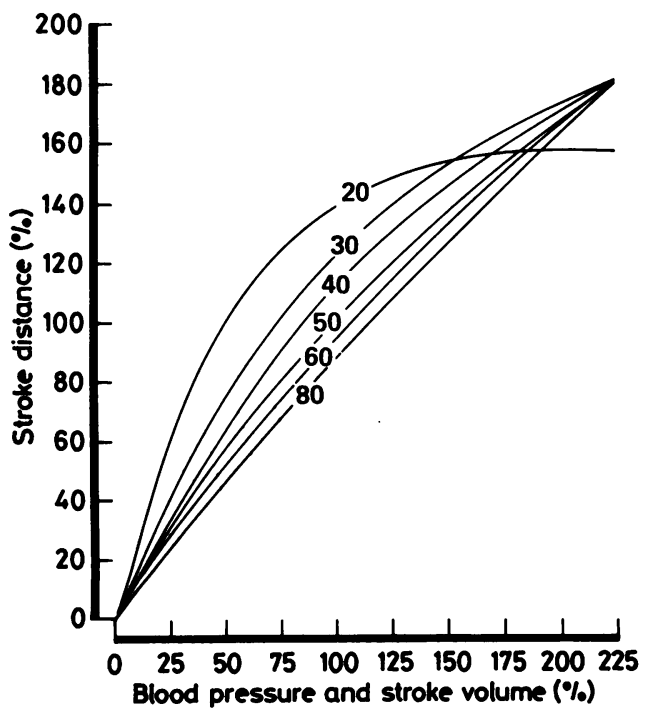

Fig. 10 Computer plot of effect of concomitant change of mean blood pressure and stroke volume on stroke distance with constant peripheral resistance. On the abscissa $100 \%$ represents a mean blood pressure of $100 \mathrm{~mm} \mathrm{Hg}$. Raw data from Bader. ${ }^{17}$ Compare with Fig. 8.

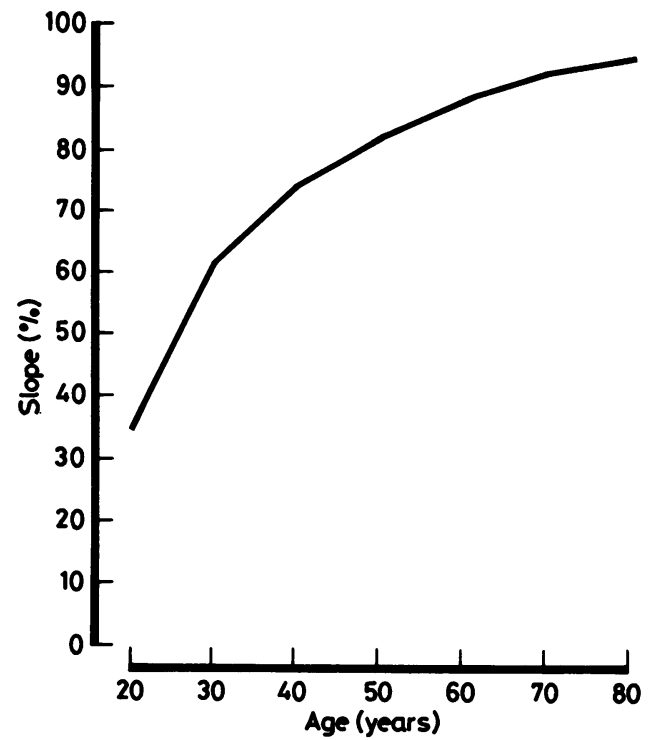

Fig. 11 The effect of age on the slope of the relation between stroke distance and stroke volume, measured at a mean blood pressure of $100 \mathrm{~mm} \mathrm{Hg}$ and assuming constant peripheral resistance.

\section{pressure.}

Assuming constant stroke volume, the predicted relation between mean blood pressure and stroke distance for blood pressures between 0 and $225 \mathrm{~mm}$ $\mathrm{Hg}$ and ages $20-80$ is seen in Fig. 9, which is essentially similar to that observed in Fig. 7 .

In Fig. 10 constant peripheral resistance is assumed and the relation between stroke volume and stroke distance is predicted for the same range of blood pressures and ages. The overall pattern is very similar to that observed in Fig. 8 and the anomalous relation between stroke volume and stroke distance at age 20 is shown in both figures. As age rises the relation becomes more linear and the slope at a mean blood pressure of $100 \mathrm{~mm} \mathrm{Hg}$ increases, until at age 80 it is $94 \%$. At this age the aorta behaves as an almost rigid pipe, and a change of stroke volume of $100 \%$ would be reflected in a change of blood velocity of $94 \%$. At lower ages, when the aorta is more distensible, the slope is reduced, reaching its lowest value of $34 \%$ at age 20 . Figure 11 shows the effect of age on the slope of the relation between stroke distance and stroke volume, measured at a mean blood pressure of $100 \mathrm{~mm} \mathrm{Hg}$ and assuming constant peripheral resistance.

\section{Discussion}

EFFECT OF AGE ON AORTIC CROSS SECTIONAL AREA

In the arch of the aorta, blood velocity and the mea- 
surements derived from it decrease with age. ${ }^{14-18}$ From their respective regression equations against age it may be estimated that at age 80 , peak aortic blood velocity, stroke distance, and minute distance are 47,39 , and $47 \%$ of their values at age 20 . This could result from reduction of volumetric cardiac output or an increase in aortic cross sectional area. In this paper we show that between the ages of 20 and 80 the cross sectional areas of the ascending and descending aorta increase by $105 \%$ and $151 \%$ respectively. In the arch of the aorta, roughly midway between these sites, the increase of cross sectional area may be estimated to have an intermediate value of $128 \%$. Since there is no reason to believe that there is any major change in the thickness of the aortic wall with age, the percentage increase in cross sectional area of the lumen is almost certainly greater than this estimate which is based on measurement of external aortic diameters. If the aortic wall thickness is assumed to be $1.5 \mathrm{~mm}$ at all ages, then the increase in the area of the lumen of the arch is about $156 \%$, sufficient to cause a fall of stroke distance to $39 \%$ of its initial value, which is exactly the fall observed.

From the regression equation given by Bader for the radius of the descending aorta at different ages, the increase in cross sectional area between age $20-80$ is $159 \%$, close to the value of $151 \%$ that we obtained.

Strehler and Schmid describe a nomogram for prediction of the external diameter of the aortic knuckle measured from a chest $x$ ray, ${ }^{19}$ but the number of measurements on which it is based is not given. At age 58, the mean age of our series, the predicted cross sectional area midway between ascending and descending aortic sections is $7.8 \mathrm{~cm}^{2}$ compared with our estimate of $7.4 \mathrm{~cm}^{2}$. The nomogram predicts an increase of cross sectional area of $101 \%$ between the ages of 20 and 80 , somewhat less than the value of $128 \%$ that we estimated for this site.

Furakawa et al measured the diameter of the aortic root in 130 patients by angiography and echocardiography. ${ }^{20}$ Though they show an increase in diameter with age, details of the regression are not given, but the cross sectional area of the aortic root appears to increase by about $74 \%$ between ages $20-80$.

There is therefore good evidence that in adults aortic size increases with age; the more proximal the measurement the less the increase. Aortic blood velocity measured in the proximal aorta would therefore be expected to be less age dependent than in the arch or descending aorta. Hatle and Angelsen reported maximal velocities in the ascending aorta in 30 normal children aged $1-16$ and in 40 adults aged
18-72. ${ }^{21}$ Although they comment that in adults velocities were lower in older patients, no details are given. Wilson et al report modal peak velocity measurements from the ascending and descending aorta in 110 normal subjects age 14 days to 35 years (mean 11.6 years). ${ }^{22}$ There was no significant relation at either site between velocity and age, but this is probably because there were too few adults in the series. In the aortic arch, the decline in velocity with age is only recognisable after the age of 20 , and in our data did not achieve statistical significance in adults under $35 .{ }^{14}$ Peak aortic blood velocity and stroke distance are remarkably constant throughout childhood. ${ }^{23}$

An alternative mechanism for the reduction of aortic blood velocity with age is a fall of volumetric cardiac output. Support for this is given by Brandfonbrener et al who measured cardiac output by dye dilution in 67 men aged $19-86 .{ }^{24}$ There was a very highly significant reduction of cardiac output with age so that the value at age 80 was $53 \%$ of that at age 20. A series of 17 patients studied by Cournand et al showed a similar rate of fall of cardiac output with age, though the regression was not significant. ${ }^{25}$ In 111 subjects in whom cardiac output was measured by the now discredited acetylene method there was a significant decline of cardiac output with age. ${ }^{26}$ If indeed there is reduction of volumetric cardiac output as well as dilatation of the aorta with age, the question posed is not why aortic blood velocity falls, but rather why it does not fall more than has been observed.

If stroke and minute distance are to be useful absolute measures of cardiac output, allowance must be made for the increase of aortic cross sectional area with age. This may be done quite simply by establishing the normal range of measurements at different ages, enabling comparisons to be adjusted for age. ${ }^{13}$

\section{ELASTICITY OF AORTA}

Greenfield and Patel studied the dynamic relation between pressure and diameter in the ascending aorta in 10 patients aged $14-55$ (mean 28) undergoing operation. ${ }^{27}$ The mean circumferential extensibility was $0 \cdot 19 \% / 1 \mathrm{~mm} \mathrm{Hg}$ pressure change. A rise of pressure from 67 to $133 \mathrm{~mm} \mathrm{Hg}$ would result in a $27 \%$ increase in cross sectional area, corresponding closely to the value of $30 \%$ that we predict for age 30. There is therefore a close agreement between prediction based on the static measurements by Bader and the observed dynamic measurements of Greenfield and Patel, though in the small number of patients that they studied the expected influence of age on circumferential extensibility did not achieve statistical significance $(r=-0.51, \mathrm{NS})$. Static and 
dynamic elastic moduli are similar in vessels such as the aorta that owe their elasticity predominantly to elastin and collagen and do not have an important muscular component. ${ }^{28}$ Thus, the theoretical relations between age, mean blood pressure, and stroke distance shown in Fig. 10 are matched by the static pressure-volume measurements of Hallock and Benson from which Fig. 8 is derived, and the dynamic measurements of Greenfield and Patel.

If serial stroke distance measurements are to be used to detect changes of volumetric cardiac output then a linear relation between them is desirable. An approximately linear relation between stroke distance and stroke volume is predicted for all ages above 30 , and even at age 20 the departure from exact linearity would have little practical importance. More disadvantageous to this method of measurement is the buffering effect of the highly elastic aorta at age 20 , so that only $34 \%$ of a change of stroke volume is reflected in a change of stroke distance, reducing the ability of the method to detect a change of flow rate. There are, however, two mitigating points. At age 20, mean blood pressure is normally about $90 \mathrm{~mm} \mathrm{Hg}$ and at this pressure the curve is somewhat steeper, and it is steeper still in the clinically important region where blood pressure is below normal. Secondly, this degree of flattening of the slope relating stroke distance and stroke volume assumes constant peripheral resistance and therefore a proportionate fall of mean blood pressure and cardiac output. In reality, blood pressure is likely to fall less than cardiac output because the former is under tighter homoeostatic control than the latter. ${ }^{29}$

In an artificial circulation that included a pig aorta we showed that the graph of minute distance against blood flow rate had a slope of $84 \%$, which was comparable to that predicted in humans at age $50 .^{7}$ Besides the slope of the relation between stroke distance and stroke volume, the ability of Doppler measurement of blood velocity to detect a change of flow rate depends on the reproducibility of the measurement. ${ }^{30}$ In this respect the method performed as well as the best thermodilution equipment tested, and the overall performance in vitro was comparable despite the adverse effect on the elasticity of the aorta.

\section{CONCLUSIONS}

For stroke distance to be a useful measure of cardiac output, aortic cross sectional area must be reasonably constant, or else change in a predictable way. The most important factors affecting aortic size in adults are age and blood pressure. The cross sectional area of the aorta more than doubles between the ages of 20 and 80 , and this is sufficient to explain the observed fall of stroke distance with age which necessitates adjustment of the results for age. At age 20 , the elasticity of the aorta causes considerable dampening of the blood velocity change resulting from a change of cardiac output if there is concomitant alteration of mean blood pressure. Above this age, elasticity is less and change of aortic size with blood pressure does not constitute a major problem.

We acknowledge a research grant from Grampian Health Board.

\section{References}

1 Magnin PA, Stewart JA, Myers S, von Ramm O, Kisslo JA. Combined Doppler and phased array echocardiographic estimation of cardiac output. Circulation 1981; 63: 388-92.

2 Huntsman LL, Stewart DK, Barnes SR, Franklin SB, Colocousis JS, Hessel EA. Noninvasive Doppler determination of cardiac output in man. Clinical validation. Circulation 1983; 67: 593-602.

3 Ihlen H, Amlie JP, Dale J, et al. Determination of cardiac output by Doppler echocardiography. Br Heart $\mathcal{f}$ 1984; 51: 54-60.

4 Chandraratna PA, Nanna M, McKay C, et al. Determination of cardiac output by transcutaneous continuous-wave ultrasonic Doppler computer. Am Heart $\mathcal{F}$ 1984; 53: 234-7.

5 Gardin JM, Dabestani A, Matin K, Allfie A, Russell D, Henry WL. Reproducibility of Doppler aortic blood flow measurements: studies on intraobserver, interobserver and day-to-day variability in normal subjects. Am $\mathcal{f}$ Cardiol 1984; 54: : 1092-8.

6 Fraser CB, Light LH, Shinebourne EA, Buchtal A, Healy MJR, Beardshaw JA. Transcutaneous aortovelography: reproducibility in adults and children. Eur $\mathcal{F}$ Cardiol 1976; 4/2: 181-9.

7 McLennan FM, Haites NE, Mackenzie JD, Daniel MK, Rawles JM. Reproducibility of linear cardiac output measurement by Doppler ultrasound alone. $\mathrm{Br}$ Heart $\mathcal{F}$ 1986; 55: 25-31.

8 Goldberg SJ, Sahn DJ, Allen HD, Valdes-Cruz LM, Hoenecke $\mathrm{H}$, Carnahan $\mathrm{Y}$. Evaluation of pulmonary and systemic blood flow by 2-dimensional Doppler echocardiography using fast Fourier transform spectral analysis. Am f Cardiol 1982; 50: 1394-400.

9 Mackay A, Been M, Rodrigues E, Murchison J, De Bono DP. Preoperative prediction of prosthesis size using cross sectional echocardiography in patients requiring aortic valve replacement. $B r$ Heart $\mathcal{f} 1985$; 53: 507-9.

10 Francis GS, Hagan AD, Dury J, O'Rourke RA. Accuracy of echocardiography for assessing aortic root diameter. Br Heart $\mathcal{F}$ 1975; 37: 376-8.

11 Elkayam U, Gardin JM, Berkley R, Hughes CA, Henry WL. The use of Doppler flow velocity measurement to assess the haemodynamic response to vasodilators in patients with heart failure. Circulation 1983; 67: 377-83.

12 Haites NE, McLennan FM, Mowat DHR, Rawles JM. 
How far is the cardiac output? Lancet 1984; ii: 1025-7.

13 Haites NE, McLennan FM, Mowat DHR, Rawles JM. Assessment of cardiac output by the Doppler ultrasound technique alone. Br Heart $\mathcal{F}$ 1985; 53: 123-9.

14 Mowat DHR, Haites NE, Rawles JM. Aortic blood velocity measurement in adults using a simple ultrasound technique. Cardiovasc Res 1983; 17: 75-80.

15 Hallock P, Benson IC. Studies on the elastic properties of human isolated aorta. $\mathcal{F}$ Clin Invest 1937; 16: 595-602.

16 Altman PL, Dittmer DS. Biological handbooks: Respiration and circulation. Bethesda: Federation of American Societies for Experimental Biology, 1971: 392-3.

17 Bader H. Dependence of wall stress in the human thoracic aorta on age and pressure. Circ Res 1967; 20: 354-61.

18 Light LH, Cross G, Rawles JM, Haites NE. Convenient monitoring of cardiac output and global left ventricular function by transcutaneous aortovelography -an update. In: Spencer M, ed. Cardiac Doppler diagnosis. 2nd ed. The Hague: Martinus Nyhoff. (In press).

19 Strehler E, Schmid P. Nomogram for determining normal diameter (aortic arch) and aortic biological age in 2-m chest $x$-rays. In: Diem $K$, Lentner $C$, eds. Documenta Geigy. Scientific tables. Macclesfield: Geigy Pharmaceuticals, 1970: inside back cover.

20 Furakawa K, Yoshikawa J, Tanaka K, et al. Echocardiographic measurement of aortic root diameter. $\mathfrak{f p n}$ Heart $\mathcal{F}$ 1976; 17: 465-70.

21 Hatle L, Angelsen B. Doppler ultrasound in cardiology: physical principles and clinical applications. 2nd ed. Philadelphia: Lea and Febiger, 1985: 93.

22 Wilson N, Goldberg SJ, Dickinson DF, Scott O. Normal intracardiac and great artery blood velocity measurements by pulsed Doppler echocardiography. $\mathrm{Br}$ Heart f 1985; 53: 451-8.

23 Light LH. Implications of aortic blood velocity measurements in children [Abstract]. $\mathcal{F}$ Physiol (Lond) 1978; 285: 17P.

24 Brandfonbrener M, Landowne M, Shock NW. Changes in cardiac output with age. Circulation 1955; 12: $557-66$

25 Cournand A, Riley RL, Breed ES, Baldwin E de F, Richards DW. Measurements of cardiac output in man using the technique of catheterisation of the right auricle or ventricle. $f$ Clin Invest 1945; 24: 106-16.

26 Aperia A. Contribution a l'etude de la physiologie de la circulation en relation avec l'age. Acta Med Scand 1938; suppl 89: 214-23.

27 Greenfield JC, Patel DJ. Relation between pressure and diameter in the ascending aorta of man. Circ Res 1962; 10: 778-81.

28 Bergel DH. The dynamic elastic properties of the arterial wall. f Physiol (Lond) 1961; 156: 458-69.

29 Dobbs WA, Prather JW, Guyton AC. Relative importance of nervous control of cardiac output and arterial pressure. Am $\mathcal{f}$ Cardiol 1971; 27: 507-12.

30 Mackenzie JD, Haites NE, Rawles JM. Method of assessing the reproducibility of blood flow measurement: factors influencing the performance of thermodilution cardiac output computers. Br Heart $\mathcal{F} 1986$; 55: 14-24. 